\title{
Karyotype Analysis in Wild Diploid, Tetraploid and Hexaploid Strawberries, Fragaria (Rosaceae)
}

\author{
Preeda Nathewet ${ }^{1, *}$, Tomohiro Yanagi ${ }^{1}$, Kim E. Hummer $^{2}$, \\ Yoshikane Iwatsubo ${ }^{3}$ and Kazuyoshi Sone ${ }^{4}$ \\ ${ }^{1}$ Faculty of Agriculture, Kagawa University, 2393 Ikenobe, Miki-cho, \\ Kita-gun, Kagawa 761-0795, Japan \\ ${ }^{2}$ USDA ARS National Clonal Germplasm Repository, 33447 Peoria Road, \\ Corvallis, Oregon 97333-2521, USA \\ ${ }^{3}$ Faculty of Science, Department of Biology, Toyama University, \\ 930 Gofuku, Toyama 930-8555, Japan \\ ${ }^{4}$ Kurume Branch, National Agricultural Research Center for Kyushu \\ Okinawa Region, 1823, Oi-cho, Kurume, Fukuoka 839-8503, Japan
}

Received August 24, 2009; accepted November 4, 2009

\begin{abstract}
Summary The strawberry, genus Fragaria (Rosaceae), has a basic chromosome of $x=7$, and is comprised of 20 wild species having an euploid series from diploid $(2 n=2 x=14)$ through decaploid $(2 n=10 x=70)$. Few karyotypes of species in this genus have been reported. The objective of this research was to determine the chromosomal morphology and karyotype analysis of wild diploid, tetraploid and hexaploid Fragaria species. Somatic chromosome images of 20 genotypes of diploids, tetraploids, and hexaploids were taken at the metaphase stage of mitosis under a light microscope. Karyotype analysis was performed in 17 accessions. The phylogenetic relationships between species were constructed using cluster analysis based on karyotypic similarity. Somatic chromosome numbers of wild diploid, tetraploid and hexaploid species were $2 n=2 x=14,2 n=4 x=28$ and $2 n=$ $6 x=42$. Chromosome morphology in wild diploid species had greater uniformity than that in the tetraploid species. Results of the cluster analysis showed that the diploid and tetraploid species reside in separate clades, with one exception. Fragaria tibetica, a tetraploid, clustered with the diploid species clade. The hexaploid, F. moschata, clustered with the tetraploid species clade.
\end{abstract}

Key words Chromosome, Fragaria, Karyotype, Polyploidy, Rosaceae, Wild strawberry.

The genus Fragaria L. is comprised of about 22 species with varying ploidy levels (Staudt $1989,1999)$. The additional taxon is the main cultivated strawberry, F. ×ananassa (8x), which originated from the spontaneous hybridization between 2 wild octoploid strawberry species, $F$. chiloensis and $F$ virginiana. Wild strawberry species are distributed through the temperate zone of Asia, Europe, North and South America. All species are restricted to a single continent or specific area, except for diploid F. vesca, which is found in both Eurasia and America (Staudt 1989, 1999). Twelve diploid species (including a hybrid species) are distributed in Asia, Europe and Western Siberia (Staudt 1999, 2003, 2005, 2006, Staudt and Dickoré 2001, Staudt et al. 2003, Staudt and Olbricht 2008). Five tetraploids are restricted to Eastern and South Eastern Asia (Staudt 2003, Staudt and Dickoré 2001), while hexaploid species occur in Europe and Western Siberia (Staudt 1989). Two wild octoploids, F. chiloensis and F. virginiana, are present in America with distribution in North and South America (Staudt 1989, 1999) while a decaploid, F. iturupensis, is endemic to Iturup in the Kuril Islands, Russia (Hummer et al. 2009).

The cytological study of strawberry plants had been carried out by Ichijima (1926) and Longley (1926). They observed that the chromosome numbers of $F$. vesca L. were diploid

\footnotetext{
*Corresponding author, e-mail: pdngw@yahoo.com
} 
Table 1. A list of the taxa used in the present study, assigned to species and summary of their origins

\begin{tabular}{|c|c|c|}
\hline Species & PI number* & Origin \\
\hline \multicolumn{3}{|l|}{ Diploid species $2 n=14$} \\
\hline Fragaria $\times$ bifera & 616613 & Besacon, France \\
\hline Fragaria bucharica & 551851 & Nathiagali, Pakistan \\
\hline Fragaria chinensis & 551576 & Hubei, China \\
\hline Fragaria manchurica & CFRA 1947 & Unknown \\
\hline Fragaria nilgerrensis & 637950 & Yunan, China \\
\hline Fragaria pentaphylla & 651570 & Unknown \\
\hline Fragaria vesca subsp. americana & 552286 & New York, USA \\
\hline Fragaria vesca subsp. americana & 552287 & New Hampshire, USA \\
\hline Fragaria vesca subsp. bracteata & 637947 & New Mexico, USA \\
\hline Fragaria vesca subsp. californica & 551513 & California, USA \\
\hline Fragaria vesca subsp. vesca & 551826 & Europe \\
\hline Fragaria vesca subsp. vesca & 637943 & Kotayk Marz, Armenia \\
\hline Fragaria vesca subsp. vesca $f$. roseiflora & 616872 & Louisiana, USA \\
\hline Fragaria viridis & 616857 & Gotland, Sweden \\
\hline Fragaria viridis & 616609 & Kaiserstuhl, Germany \\
\hline \multicolumn{3}{|l|}{ Tetraploid species $2 n=28$} \\
\hline Fragaria corymbosa & CFRA 1911 & Qinghai, China \\
\hline Fragaria orientalis & 602942 & Jili, China \\
\hline Fragaria orientalis & 551864 & Russia Federation** \\
\hline Fragaria tibetica & 651567 & Unknown \\
\hline Fragaria tibetica & CFRA 1908 & Qing Hai, China \\
\hline \multicolumn{3}{|l|}{ Hexaploid species $2 n=42$} \\
\hline Fragaria moschata & 551550 & Unknown \\
\hline
\end{tabular}

* all accessions are maintained at NCGR, Corvallis, USA.

** Now classified as "F. hybrid" by NCGR due to the questionable pedigree.

$(2 n=x=14), F$. moschata Weston, hexaploid $(2 n=6 x=42)$, and $F$. chiloensis (L.) Miller and $F$. virginiana Miller were octoploid $(2 n=8 x=56)$. In the same year, Ichijima (1926) determined the basic chromosome numbers of the genus Fragaria as $x=7$, with 4 main ploidy levels ranging for diploid $(2 n=2 x=14)$, tetraploid $(2 n=4 x=28)$, hexaploid $(2 n=6 x=42)$, and octoploid $(2 n=8 x=56)$. Subsequently, observations of chromosomes of wild and cultivated strawberry plants have been conducted to confirm the ploidy level (Longley 1926, Petrov et al. 1962, Bringhurst and Khan 1963, Bringhurst and Gill 1970, Bringhurst and Senanayake 1966, Hummer et al. 2009, Kafkas et al. 2002, Nathewet et al. 2007, Owen and Miller 1993, Yamaguchi 1980, Yarnell 1929, 1931a, b). Cytologists have also studied the pollen mother cell of strawberry plants to classify the phylogenetic relationship between parent and progeny and genome compositions (Fedorova 1934, Ibrahim et al. 1981, Kihara 1930, Scott 1950, Senanayake and Bringhurst 1967, Staudt et al. 2003, Yarnell 1931b). Furthermore, karyotype analyses have been conducted on 6 wild diploid species, $F$. daltoniana J. Gay, F. hayatai Makino, F. iinumae Makino, F. nipponica Makino, F. nubicola (Hook. f.) Lindl. ex Lacaita, and F. vesca L., to describe the karyotypic differences among these species (Iwatsubo and Naruhashi 1989, 1991, Naruhashi et al. 1999, Lim 2000, Nathewet et al. 2009). Nathewet et al. (2009) recently exhibited 56 chromosomes one by one in a wild octoploid plant of F. chiloensis.

To date, a great number of studies using morphological and molecular biological data have been performed to clarify the genetic relashionship among some Fragaria species including wild diploids, tetraploids, hexaploids, and octoploids (Catling and Porebski 1998, Hadonou et al. 2004, Harrison et al. 1997, Hokanson et al. 1993, Hokanson et al. 2006, Potter et al. 2000). However, few papers have reported karyotype analysis of diploid, tetraploid, or hexaploid strawberry plants, or 


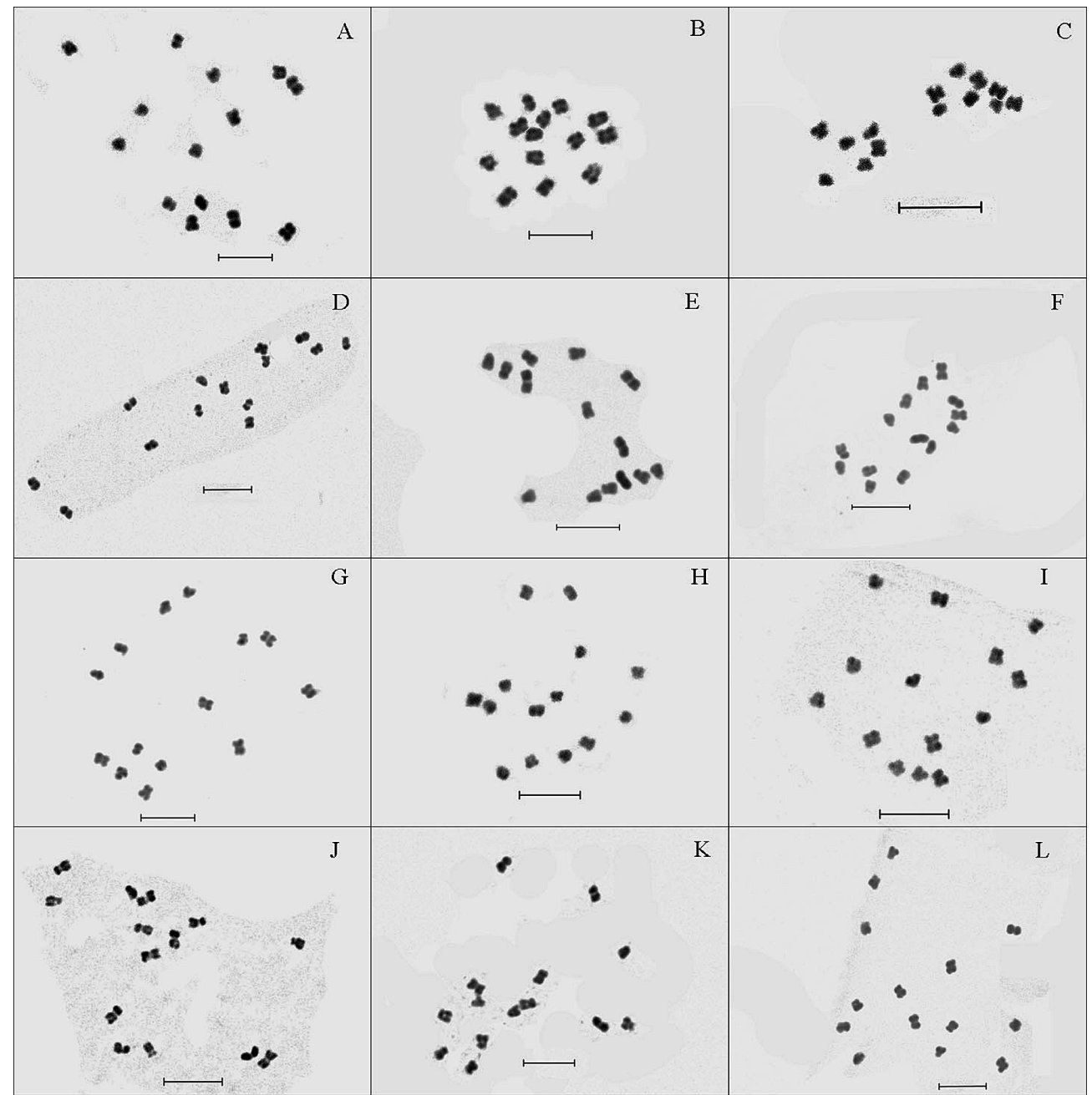

Fig. 1. Somatic chromosomes at the metaphase stage in root tip cells of wild diploid strawberries, all species with $2 n=14$. (A) F $\times$ bifera PI 616613. (B) F. bucharica PI 551851. (C) F. gracilis PI ? (CFRA202). (D) F. mandshurica, CFRA 1947. (E) F. nilgerrensis PI 637950. (F) F. pentaphylla PI 651570. (G) F. vesca subsp. americana PI 552287. (H) F. vesca subsp. bracteata PI 637947. (I) F. vesca subsp. californica PI 551513. (J) F. vesca subsp. vesca PI 551826. (K) F. vesca subsp. roseiflora PI 616872. (L) F. viridis PI 616609. The scale bars indicate $5 \mu \mathrm{m}$.

have explored the relationship among them through karyotypic analyses. The objective of this study was to compare the karyotype features among diploid, tetraploid, and hexaploid wild strawberry species, and to propose a phylogeny for them based on karyotypic similarity.

\section{Materials and methods}

The somatic chromosomes of 22 genotypes of diploid, tetraploid, and hexaploid wild strawberry species (Table 1) maintained at USDA, ARS, National Clonal Germplasm Repository (NCGR) Corvallis, Oregon, USA, were observed. Root tips were harvested and pretreated with $2 \mathrm{mM} 8$-hydroxyquinoline at room temperature $\left(22^{\circ} \mathrm{C}\right)$ for $1 \mathrm{~h}$ and then kept at $4^{\circ} \mathrm{C}$ for $15 \mathrm{~h}$. The 


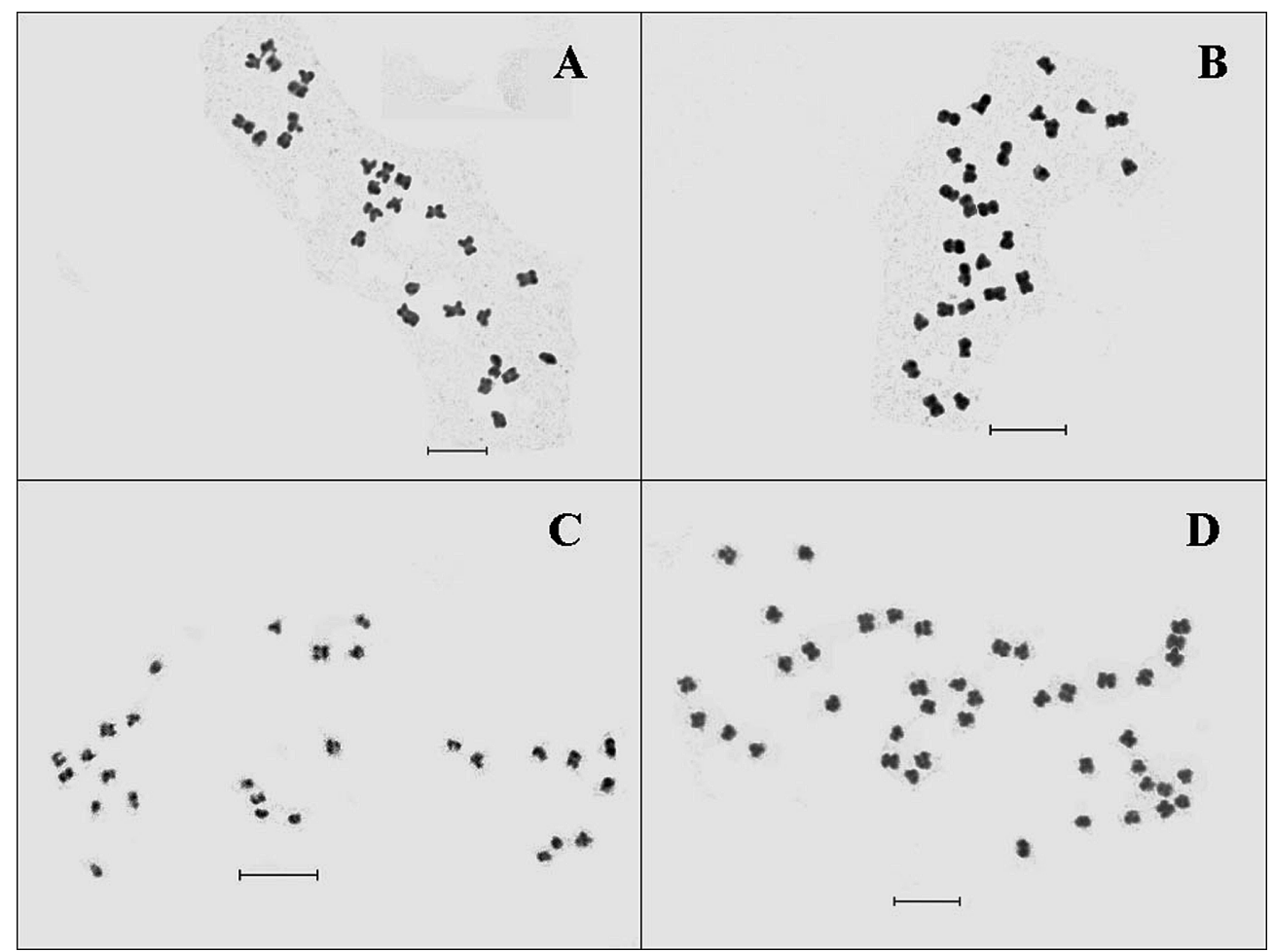

Fig. 2. Mitotic metaphase chromosomes in root tip cells of tetraploid strawberry F. corymbosa PI 602942, $2 n=28$ (A), F. orientalis PI 551864, $2 n=28$ (B), F. tibetica, PI 651567, $2 n=28$ (C), and hexaploid strawberry F. moschata PI 551550, $2 n=42$ (D). The scale bars indicate $5 \mu \mathrm{m}$.

root tips were subsequently fixed in Farmer's solution (3:1 absolute ethanol: glacial acetic acid), soaked in $1 \mathrm{~N} \mathrm{HCl}$ at $22^{\circ} \mathrm{C}$ for $1 \mathrm{~h}$, macerated in $1 \mathrm{~N} \mathrm{HCl}$ at $60^{\circ} \mathrm{C}$ for $11 \mathrm{~min}$, and rinsed twice with distilled water. Root tips were stained and squashed with $1.5 \%$ lacto-propionic orcein solution. That procedure was similar to that used by Iwatsubo and Naruhashi $(1989,1991)$ and by Nathewet et al. (2007, 2009). Chromosomes were observed and photographed at $100 \times$ objective using a light microscope (BX51: Olympus Corp., Tokyo, Japan) equipped with a 3CCD camera (XD500: Olympus Corp., Tokyo, Japan).

For each genotype, at least 10 clear images of somatic cells at the metaphase stage were used to count the chromosomes. Then, for each genotype, 4 of the best images were selected for measuring the long and short arm length. The respective lengths of the long arm (La) and short arm (Sa) of each chromosome were measured using software (FLVFS-FIS: Flovel Co. Ltd., Tokyo, Japan). The nomenclature used for description of chromosome morphology was proposed by Levan et al. (1964). Metacentric (m), sub-metacentric (sm) and sub-telocentric (st) chromosomes were noted. As suggested by Levan et al. (1964), the following parameters were estimated in each metaphase image to characterize the karyotype numerically: (1) total chromosome length $(\mathrm{TCL}=\Sigma \mathrm{La}+\Sigma \mathrm{Sa})$; (2) arm ratio $(\mathrm{AR}=\Sigma \mathrm{La} / \Sigma \mathrm{Sa})$; (3) mean haploid chromosome length (MCL) and centromeric index $(\mathrm{CI}=100 \times \Sigma \mathrm{Sa} /(\Sigma \mathrm{La}+\Sigma \mathrm{Sa}))$. A cluster analysis using Ward's method in JMP software (SAS Inc.) was conducted using karyotype numerical data. Variations for HCL, MCL, and CI among species were verified using one-way analysis of variance. Comparisons of means were made using the Tukey-Kramer HSD test at $P<0.05$. 
Table 2. Chromosome numbers, karyotype formulae, mean chromosome length (MCL), total chromosome length (TCL), centromeric index (CI). Chromosome abbreviations: $\mathrm{m}=$ metacentric, $\mathrm{sm}=$ submetacentric, and $\mathrm{st}=$ subtelocentric.

\begin{tabular}{|c|c|c|c|c|c|c|c|}
\hline Species & PI number & $\begin{array}{l}\text { Chro. } \\
\text { No. }\end{array}$ & $\begin{array}{l}\text { Karyotype } \\
\text { formulae }\end{array}$ & $\begin{array}{l}\text { Range } \\
(\mathrm{mm})\end{array}$ & $\begin{array}{l}\mathrm{TCL} \\
(\mu \mathrm{m})\end{array}$ & $\begin{array}{l}\mathrm{MCL} \\
(\mathrm{mm})\end{array}$ & CI $\%$ \\
\hline Fragaria bucharica & 551851 & 14 & $8 m+6 s m$ & $0.89-1.45$ & $17.00 \mathrm{e}$ & $1.21 \mathrm{abc}$ & $38.31 \mathrm{a}$ \\
\hline Fragaria $\times$ bifera & 616613 & 14 & $8 m+6 s m$ & $0.89-1.33$ & $15.63 \mathrm{e}$ & $1.12 \mathrm{abcd}$ & $37.09 \mathrm{a}$ \\
\hline Fragaria chinensis & 551576 & 14 & $8 m+6 s m$ & $0.61-0.93$ & $11.00 \mathrm{f}$ & $0.79 \mathrm{e}$ & $35.86 \mathrm{a}$ \\
\hline Fragaria manchurica & CFRA 1947 & 14 & $10 \mathrm{~m}+4 \mathrm{sm}$ & $0.91-1.40$ & $15.76 \mathrm{e}$ & $1.13 \mathrm{abcd}$ & $38.54 \mathrm{a}$ \\
\hline Fragaria nilgerrensis & 637950 & 14 & $8 m+6 s m$ & $1.12-1.60$ & $18.29 \mathrm{e}$ & $1.31 \mathrm{a}$ & $37.70 \mathrm{a}$ \\
\hline Fragaria pentaphylla & 651570 & 14 & $10 \mathrm{~m}+2 \mathrm{sm}+2 \mathrm{st}$ & $0.97-1.49$ & $16.51 \mathrm{e}$ & $1.18 \mathrm{abc}$ & $37.32 \mathrm{a}$ \\
\hline Fragaria vesca subsp. americana & 552287 & 14 & $10 \mathrm{~m}+4 \mathrm{sm}$ & $0.82-1.24$ & $14.89 \mathrm{ef}$ & $1.06 \mathrm{bcd}$ & $39.50 \mathrm{a}$ \\
\hline Fragaria vesca subsp. bracteata & 637947 & 14 & $10 \mathrm{~m}+4 \mathrm{sm}$ & $0.84-1.20$ & $14.48 \mathrm{ef}$ & $1.03 \mathrm{bcd}$ & $38.50 \mathrm{a}$ \\
\hline Fragaria vesca subsp. californica & 551513 & 14 & $10 \mathrm{~m}+4 \mathrm{sm}$ & $0.86-1.20$ & $14.25 \mathrm{ef}$ & $1.02 \mathrm{cde}$ & $38.79 a$ \\
\hline Fragaria vesca subsp. vesca & 551826 & 14 & $8 m+4 s m+2 s t$ & $0.80-1.27$ & $14.58 \mathrm{ef}$ & $1.04 \mathrm{bcd}$ & $37.42 \mathrm{a}$ \\
\hline Fragaria vesca subsp. vesca f. roseiflora & 616872 & 14 & $8 m+4 s m+2 s t$ & $0.97-1.36$ & $16.36 \mathrm{e}$ & $1.17 \mathrm{abc}$ & $38.34 \mathrm{a}$ \\
\hline Fragaria viridis & 616609 & 14 & $8 m+6 s m$ & $0.87-1.28$ & $15.19 \mathrm{ef}$ & $1.09 \mathrm{abcd}$ & $38.18 \mathrm{a}$ \\
\hline Fragaria corymbosa & CFRA 1911 & 14 & $16 m+12 s m$ & $0.77-1.36$ & $28.69 \mathrm{~cd}$ & $1.02 \mathrm{cde}$ & $37.91 \mathrm{a}$ \\
\hline Fragaria orientalis & 602942 & 28 & $12 \mathrm{~m}+16 \mathrm{sm}$ & $0.93-1.85$ & $36.26 \mathrm{~b}$ & $1.29 \mathrm{ab}$ & $35.21 \mathrm{a}$ \\
\hline Fragaria orientalis & 551864 & 28 & $14 m+14 s m$ & $0.93-1.57$ & $31.35 \mathrm{bc}$ & $1.13 \mathrm{abc}$ & $39.08 \mathrm{a}$ \\
\hline Fragaria tibetica & 651567 & 28 & $18 \mathrm{~m}+10 \mathrm{sm}$ & $0.69-1.15$ & $24.99 \mathrm{~d}$ & $0.89 \mathrm{de}$ & $37.48 \mathrm{a}$ \\
\hline Fragaria moschata & 551550 & 42 & $30 m+10 s m+2 s t$ & $0.83-1.27$ & $43.54 \mathrm{a}$ & $1.04 \mathrm{bcd}$ & $38.85 \mathrm{a}$ \\
\hline$F($ ANOVA $) P=0.05$ & & & & & 100.8671 & 8.2418 & 1.6616 \\
\hline$P$ value & & & & & $<0.0001$ & $<.0001$ & $<0.0842$ \\
\hline Fragaria vesca subsp. americana & 552286 & 14 & - & - & - & - & - \\
\hline Fragaria vesca subsp. vesca & 637943 & 14 & - & - & - & - & - \\
\hline Fragaria viridis & 616857 & 14 & - & - & - & - & - \\
\hline Fragaria tibetica & CFRA 1908 & 28 & - & - & - & - & - \\
\hline
\end{tabular}

Note: Values in the same column with different laters are significantly different.

\section{Results}

Somatic chromosome images at the metaphase stage of the studied taxa are shown (Figs. 1,2). The chromosome number for each accession is presented (Table 2). The somatic chromosome number of all wild diploid, tetraploid and hexaploid strawberries is $2 n=2 x=14,2 n=4 x=28$, and $2 n=6 x=42$, respectively.

The karyotype formulae obtained and parameters analyzed for each accession are shown in Table 2. Among diploid species, the most common karyotype formula was $8 \mathrm{~m}+6 \mathrm{sm}$ for $F$. bucharica Losinsk. PI 551851, F. $\times$ bifera Duchesne PI 616613, F. chinesensis PI 551576 and $F$. nilgerrensis Schltdl. ex J. Gay PI 637950, and followed in frequency of $10 \mathrm{~m}+4 \mathrm{sm}$ for $F$. mandshurica CFRA 1947, F. vesca subsp. americana (Porter) Staudt PI 552287, F. vesca subsp. bracteata (A. Heller) Staudt PI 637947 and F. vesca subsp. californica (Cham. and Schltdl.) Staudt PI 551513. On the other hand, F. vesca subsp. vesca PI 551826 and F. vesca subsp. vesca f. roseiflora (Boulay) Staudt PI 616872 had a karyotype formula as $8 \mathrm{~m}+4 \mathrm{sm}+2 \mathrm{st}$, and $F$. pentaphylla PI 651570 had $10 \mathrm{~m}+2 \mathrm{sm}+2 \mathrm{st}$. The karyotype features of the tetraploid species accessions presented only $\mathrm{m}$ and sm chromosomes. F. tibetica Staudt \& Dickoré PI 651567 had the highest number of $\mathrm{m}$ chromosomes among the tetraploids. The karyotype formula of $F$. moschata PI 551550 was $30 \mathrm{~m}+10 \mathrm{sm}+2 \mathrm{st}$ (Table 2). In addition, except for F. orientalis Losinsk. PI 602942, in most karyotypes, the longest pairs of chromosome complements were the m chromosome (Fig. 4).

The range of chromosome lengths was $0.61-0.93 \mu \mathrm{m}$ in F. chinensis PI 651567 and $0.93-1.85 \mu \mathrm{m}$ in $F$. orientalis PI 602942 (Table 2). The TCL value varied significantly from $11.00 \mu \mathrm{m}$ in F. chinensis PI 551576 to $43.54 \mu \mathrm{m}$ in F. moschata PI 551550. The highest value of 


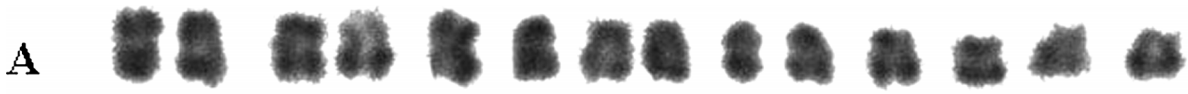 \\ a

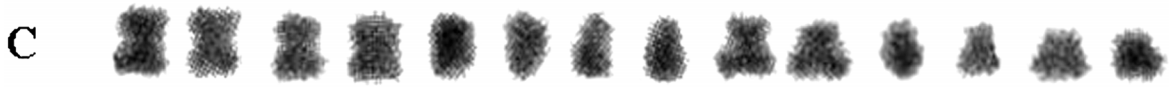

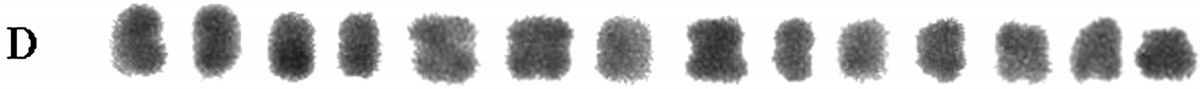

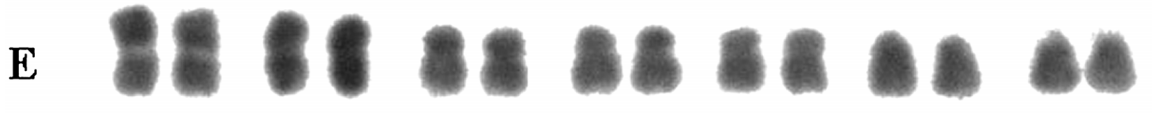 \\ F 18 I8 an ac at an os}

c 3 要

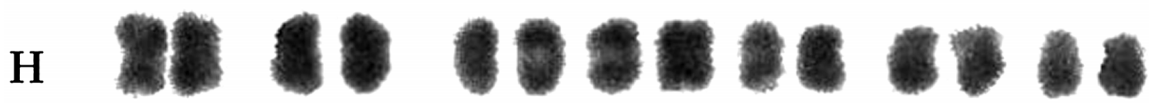

I 8 औ

ง หับข

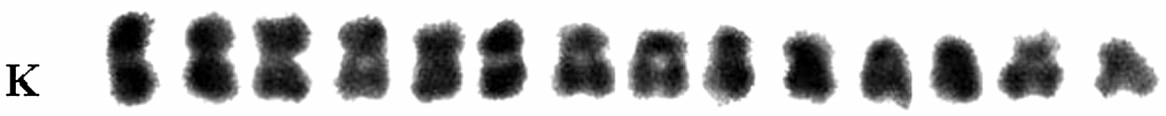

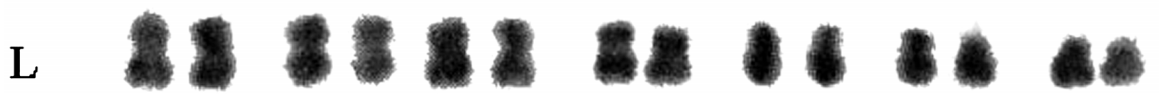

Fig. 3. The karyotypes of wild diploid strawberries species. (A). F. $\times$ bifera PI 616613. (B) F. bucharica PI 551851. (C) F. chinensis CFRA202. (D) F. mandshurica CFRA 1947. (E) F. nilgerrensis PI 637950. (F) F. pentaphylla PI 651570. (G) F. vesca subsp. americana PI 552287. (H) F. vesca subsp. bracteata PI 637947. (I) F. vesca subsp. californica PI 551513. (J) F. vesca subsp. vesca PI 551826. (K) F. vesca subsp. roseiflora PI 616872. (L) F. viridis PI 616609.

TCL $(43.54 \mu \mathrm{m})$ was observed in F. moschata PI 551550. The longest and shortest MCL was $1.31 \mu \mathrm{m}$ for $F$. nilgerrensis PI 637950 and $0.79 \mu \mathrm{m}$ for $F$. chinensis PI 616699 . There were no significant differences in the CI values for all accessions. The highest CI value of 39.50 was observed in F. vesca subsp. americana PI 552287. F. chinensis PI 551576 and F. orientalis Losinsk. PI 602942 exhibited lower CI values than other species. 


\section{A

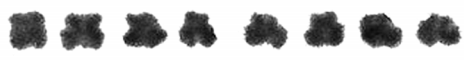

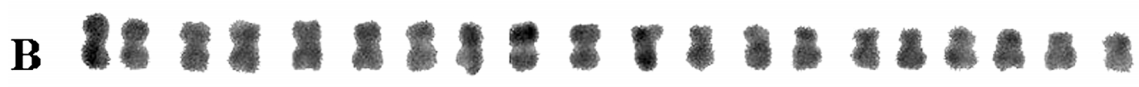

\section{ban ona

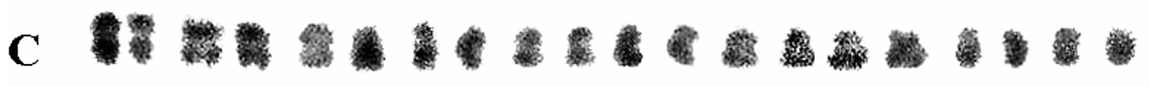

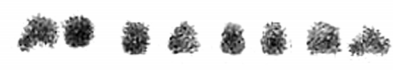

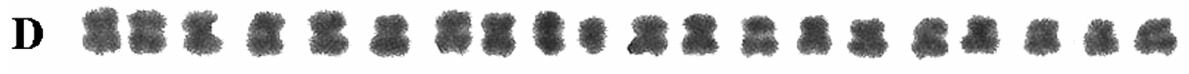

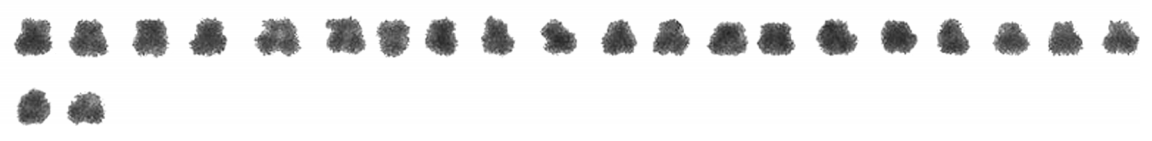

Fig. 4. The karyotype of tetraploid strawberries $(2 n=28)$, F. orientalis PI 602942 (A), F. corymbosa CFRA 1911. (B), F. tibetica PI 651567 (C), and hexaploid strawberry $(2 n=42)$, F. moschata PI 551550 (D). Arrows indicate the largest sm chromosome pairs, which might be the pair of sex chromosomes.

A dendrogram constructed based on the numerically karyotype data showed two major clades (Fig. 5). The first clade included all of the diploid species, and one tetraploid accession, F. tibetica PI 651567. Within this major cluster the wild Eurasia diploid species were classified as members of the same sub-subclade, with the exception of F. pentaphylla PI 651570, and differ from the accessions of $F$. vesca subspecies from America and Europe. The second major clade was comprised of the wild tetraploid F. corymbosa CFRA 1911, F. orientalis PI 551864, F. orientalis PI 602942, and hexaploid F. moschata PI 551550 accessions.

\section{Discussion}

The results of chromosome counting confirmed that the somatic chromosomes of wild diploid, tetraploid and hexaploid strawberry species were $2 n=2 x=14,2 n=4 x=28$ and $2 n=6 x=42$, respectively (Table 2). These results were consistent with descriptions in previous reports (Darrow 1966, Ichijima 1926, Iwatsubo and Naruhashi 1989, 1991, Lilienfeld 1933, Lim 2000, Naruhashi et al. 1999, Nathewet et al. 2007, Staudt 1999, 2003, 2005, 2006, Staudt and Dickoré 2001, Staudt et al. 2003, Yarnell 1929). This study is also the first report of some previously unreported karyotypes for diploid (F. bucharica, F. $\times$ bifera, F. chinensis, F. nilgerrensis, F. pentaphylla, F. viridis and subspecies of $F$. vesca), tetraploid (F. orientalis, F. corymbosa and F. tibetica) and hexaploid ( $F$. moschata). The results of karyotype analysis for the diploid species in this study are similar with the results for diploid Fragaria (Iwatsubo and Naruhashi 1989, 1991).

Our results also confirmed that the chromosome lengths of wild strawberry plants in genus 


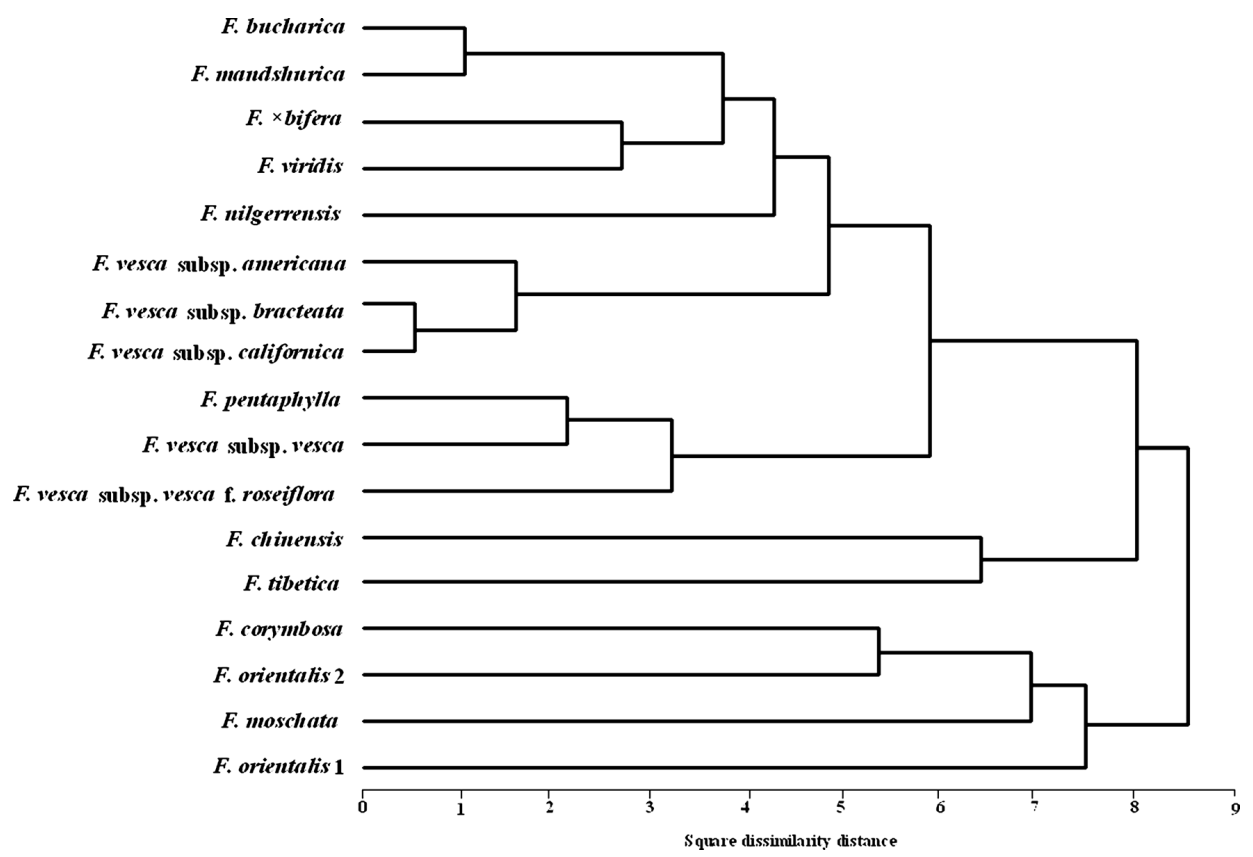

Fig. 5. Dendrogram demonstrating phenetic relationships among the diploid, tetraploid and hexaploid species in Fragaria.

Fragaria were small (Iwatsubo and Naruhashi 1989, 1991, Nathewet et al. 2007, Naruhashi et al. 1999, Yamaguchi 1980). The mean chromosome length for the diploid, tetraploid and hexaploid species was $1.09 \mu \mathrm{m}$. The total chromosome lengths in each species increased according to their ploidy level. The highest value of TCL $(43.54 \mu \mathrm{m})$ was recorded in F. moschata, a hexaploid. In addition, the present study suggested that each diploid species had a greater uniformity in karyotype formulae and similarity of quantitative data than the tetraploid species. Particularly, the karyotype formulae, TCL and CI values among the Asian wild diploid species were similar and consistent. This finding is consistent with that of Iwatsubo and Naruhashi (1989, 1991), who reported that of 5 diploid Fragaria, F. daltoniana, F. nipponica, F. nubicola, and F. vesca displayed similar karyotype morphology to each other, while $F$. iinumae was significantly distinctly related to the other diploids. In addition, our results have shown that the tetraploid species have a similar karyotype formula but their TCL differs, suggesting that the addition of genetic material may also be involved in their karyotype evolution. Although, in this study, the karyotypic differences that we observed among the diploids and tetraploids were small, the species could be differentiated by the number and type of chromosomes, and statistical differences of the means of numerical data such as TCL, MCL and CI values.

Furthermore, in most karyotypes, the longest pairs of complements were $\mathrm{m}$ chromosomes. Surprisingly, the longest pair of chromosomes in F. orientalis PI 602942 was the largest sm chromosome pair. The largest sm chromosomes of PI 602942 in F. orientalis were confirmed using more than 10 root tips, and those chromosomes exist in almost all somatic cells. These chromosomes might be sex chromosomes of F. orientalis PI 602942 (Fig. 4A) because the plant in this species consists of dioecious and trioecious populations (Staudt 2003). The existence of sex chromosomes had been reported in the pollen mother cells of hexaploid F. moschata (Kihara, 1930). Recently, Nathewet et al. (2009) reported sex chromosomes in the mitotic cells of staminate male $F$. chiloensis plants. In this study, however, we were not able to confirm the identity of the sex chromosomes in mitotic cells of F. moschata. 
Karyotype similarities were evaluated using cluster analysis to clarify phylogenetic relations among or within the species of diploid, tetraploid, and hexaploid species (Fig. 5). The wild diploid and tetraploid species, with the exception of the tetraploid, F. tibetica PI 651567, could be clearly separated using gross karyotype morphology. These species can also be separated based on morphological, cytological, ecological characteristics and molecular marker analysis (Hadonou et al. 2004, Potter et al. 2000, Staudt 1962, 1989, 1999, 2003, 2006, Staudt and Dickoré 2001, Staudt et al. 2003). Our cluster analysis suggested that most wild Eurasian diploid species accessions clustered together, but the American and European F. vesca subspecies were distinct. Sargent et al. (2004) and Potter et al. (2000) reported distinct morphological and molecular biology aspects, respectively, between $F$. vesca accessions and other diploids. This is reflected by the geographical distribution and genetic and morphological distinctness of these species. Within the group of wild Eurasian diploid species, $F \times$ bifera clustered with $F$. viridis, which was to be expected, as $F$. viridis is known to be a parental F. $\times$ bifera (Staudt et al. 2003). Furthermore, the American subspecies of $F$. vesca ( $F$. vesca subsp. americana, $F$. vesca subsp. bracteata and $F$. vesca subsp. californica) were clearly separated from the F. vesca subsp. vesca from Europe (Fig. 5), reaffirming the long genetic divergence of the American and European F. vesca subspecies. These different relationships were consistent with results of non-coding nuclear sequences analyses (Potter et al. 2000). Hadonou et al. (2004) also reported high similarity of molecular biological aspects among American F. vesca subspecies. For tetraploid species, the analysis of phylogenetic relationships based on molecular and biological aspects showed that all tetraploid species were clustered in the same group (Potter et al. 2000, Rousseau-Gueutin et al. 2009). In contrast, our results showed that F. tibetica PI 651567 was grouped with the diploid species, $F$. chinensis and separated from the tetraploid group. Moreover, F. moschata clustered in the same clade with the tetraploid species, F. orientalis and $F$. corymbosa, indicating that $F$. moschata is closely related to the tetraploid species. This relationship was supported by Harrison et al. (1997) and Potter et al. (2000) who claimed that these 2 species are indeed sister taxa. However, there are some questions about morphological classification of $F$. orientalis PI 551864, which was also used in a previous study (Harrison et al. 1997, Potter et al. 2000). This particular accession presumably derived from open pollination and may not be pure $F$. orientalis, so the NCGR is now classified as a hybrid. Moreover, the parents of $F$. orientalis PI 551864 are still unknown. If the maternal plants were correctly labeled, then our results may accurately represent the $F$. orientalis karyotype.

\section{References}

Bringhurst, R. S. and Gill, T. 1970. Origin of Fragaria polyploids: unreduced and double unreduced gametes. Am. J. Bot. 53: 1000-1006.

— and Khan, D. A. 1963. Natural pentaploid Fragaria chiloensis-F. vesca hybrids in coastal California and their significance in polyploidy Fragaria evolution. Am. J. Bot. 50: 658-661.

— and Senanayake, Y. D. A. 1966. The evolutionary significance of natural Fragaria chiloensis $\times$. vesca hybrids resulting from unreduced gametes. Am. J. Bot. 57: 969-976.

Catling, P. M. and Porebski, S. 1998. A morphometric evaluation of the subspecies of Fragaria chiloensis. Can. J. Bot. 76: 290-297.

Darrow, G. 1966. The Strawberry. Holt, Rinehart and Winston, New York, Chicago, and San Francisco.

Fedorova, N. 1934. Polyploids inter-specific hybrids in the genus Fragaria. Genetica 16: 525-541.

Hadonou, A. M., Sargent, D. J., Wilson, F., James, C. K. and Simpson, D. W. 2004. Development of microsatellite markers in Fragaria, their use in genetic diversity analysis, and their potential for genetic linkage mapping. Genome 47 429-438.

Harrison, R. E., Luby, J. J. and Furnier, G. R. 1997. Chloroplast DNA restriction Fragment Variation among Strawberry (Fragaria spp.) Taxa. J. Amer. Soc. Hort. Sci. 122: 63-68.

Hokanson, K. E., Harrison, R. E., Luby, J. J. and Hancock J. F. 1993. Morphological variation in Fragaria virginiana from the Rocky Mountains. Acta. Hort. 348: 94-101.

—, Smith, M. J., Connor, A. M., Luby J. J. and Hancock J. F. 2006. Relationships among subspecies of New World 
octoploid strawberry species, Fragaria virginiana and Fragaria chiloensis, based on simple sequence repeat marker analysis. Can. J. Bot. 84: 1829-1841.

Hummer, K., Nathewet, P. and Yanagi, T. 2009. Decaploidy in Fragaria iturupensis (Rosaceae). Am. J. Bot. 96: 1-5.

Ichijima, K. 1926. Cytological and genetic studies on Fragaria. Genetics 11: 590-604.

Ibrahim, A. M., Sadanaga, F. K. and Denisen, E. L. 1981. Chromosomes behavior in octoploid strawberry progenies and their parental clones during meiosis. J. Amer. Soc. Hort. Sci. 106: 522-526.

Iwastubo, Y. and Naruhashi, N. 1989. Karyotypes of three species of Fragaria (Rosaceae). Cytologia 54: $493-497$.

— and - 1991. Karyotypes of Fragaria nubicola and F. daltoniana. Cytologia 56: 453-457.

Kafkas, E., Paydas, S. and Celiktas, N. 2002. Studies on chromosome counting of strawberry root cells. Acta. Hort. 567: 235-237.

Kihara, H. 1930. Karyologishe studien an Fragaria mit besonderer Berück-sichtinung der gechlechtschromosomen. Cytologia 1: 345-357 (in German).

Lilienfeld, F. 1933. Karyologische und genetische Studien an Fragaria L. Ein tetraploider fertiler Bastard zwischen F. nipponica $(n=7)$ und F. elatior $(n=21)$. Jpn. J. Bot. 6: 425-458 (in German).

Lim, K. Y. 2000. Karyotype and ribosomal gene mapping in Fragaria vesca L. Acta. Hort. 649: 103-106.

Levan, A., Fredga, K. and Sanberge, A. A. 1964. Nomenclature for centromeric position on chromosomes. Hereditas 52: 201-220.

Longley, A. E., 1926. Chromosomes and their significance in strawberry classification. J. Agri. Res. 15: 559-568.

Nathewet, P., Yanagi, T., Iwatsubo, Y., Sone, K., Tamura, T. and Okuda, N. 2009. Improvement of staining method for observation of mitotic chromosome in octoploid strawberry plants. Sci. Hort. 120: 431-435.

- , - Sone, K., Taketa, S, and Okuda, N. 2007. Chromosome observation method at metaphase and pro-metaphase stages in diploid and octoploid strawberries. Sci. Hort. 114: 133-137.

Naruhashi, N., Iwatsubo, Y. and Peng, C. I. 1999. Cytology, flower morphology and distribution of Fragaria hayatai Makino (Rosaceae). J. Phytogeogr. Taxon. 47: 139-143.

Owen, H. R. and Miller, A. R. 1993. A comparison of staining techniques for somatic chromosome of strawberry. Hort. Sci. 28: 115-116.

Petrov, D. F., Sankin, L. S. and Krylova, G. V. 1962. A polyploid form of Fragaria orientalis Los. Nature 13: 199.

Potter, D., Luby, J. J. and Harrison, R. E. 2000. Phylogenetic relationships among species of Fragaria (Rosaceae) inferred from non-coding nuclear and chloroplast DNA sequences. Syst. Bot. 25: 337-348.

Rousseau-Gueutin, M., Gaton, A., Aïouche, M. L., Nouche, A., Olbricht, K., Staudt, G., Richard, L. and Denoyes-Rothan, B. 2009. Tracking the evolutionary history of polyploid in Fragaria L. (Strawberry): New insights from phylogenetic analyses of low-copy nuclear genes. Mol. Phylogenet. Evol. 51: 515-530.

Sargent, D. J., Geibel, M., Hawkins, J. A., Wilkinson, M. J., Battey, N. H. and Simpson, D. W. 2004. Quantitative and qualitative differences in morphological traits revealed between diploid Fragaria species. Ann. Bot. 94: 787-796.

Scott, D. H., 1950. Cytological studies on polyploids derived from tetraploid Fragaria vesca and cultivated strawberries. Genetics 36: 311-331.

Senanayake, Y. D. A., Bringhurst, R. S. 1967. Origin of Fragaria polyploids. I. Cytological analysis. Amer. J. Bot. 57: 969-976.

Staudt, G. 1962. Taxonomic studies in the genus Fragaria: typification of Fragaria species known at the time of Linnaeus. Can. J. Bot. 40: 869-886.

- 1989. The species of Fragaria, their taxonomy and geographical distribution. Acta. Hort. 265: 23-33.

— 1999. Notes on Asiatic Fragaria species: Fragaria nilgerrensis Schltdl. ex J. Gay. Bot. Jahrb. Syst. 121: 297-310.

- 2003. Notes on Asiatic Fragaria species: III. Fragaria orientalis Losinsk. and Fragaria mandshurica spec. nov. Bot. Jahrb. Syst. 124: 397-419.

— 2005. Notes on Asiatic Fragaria species: IV. Fragaria iinumae Losinsk. Bot. Jahrb. Syst. 126: 163-175.

- 2006. Himalayan species of Fragaria (Rosaceae). Bot. Jahrb. Syst. 124: 483-508.

— and Dickoré, W. B. 2001. Notes on Asiatic Fragaria species: Fragaria pentaphylla Losinsk. and Fragaria tibetica spec. nov. Bot. Jahrb. Syst. 123: 341-354.

-, DiMeglio, L. M., Davis, T. M. and Gerstberger, P. 2003. Fragaria $\times$ bifera Duch.: Origin and taxonomy. Bot. Jahrb. Syst. 125: 53-72.

— and Olbricht, K. 2008. Notes on Asiatic Fragaria species V: F. nipponica and Notes F. iturupensis. Bot. Jahrb. Syst. 127: 317-341.

Yamaguchi, S. 1980. Cytogenetics in horticultural plant, II. Chromosome number of six leading cultivars of strawberry (Fragaria $\times$ ananassa) in Japan. La kromosomo II 17: 487-489 (in Japanese with English abstract).

Yarnell, S. H. 1929. Notes on the somatic chromosomes of the seven-chromosome group of Fragaria. Genetics 14: 79-83.

- 1931a. Genetic and cytological studies on Fragaria. Genetics 16: 422-454.

- 1931b. A study of certain polyploidy and aneuploid forms in Fragaria. Genetics 16: 455-489. 